\title{
Association of Common Vitamin D Receptor Gene Variations with Fracture Risk and Bone Mineral Density in Postmenopausal Korean Population
}

\author{
Joo-Yeon Hwang ${ }^{1 \dagger}$, Seung Hun Lee ${ }^{2,4 \dagger}$, Ghi \\ Su Kim ${ }^{2,4}$, Jung-Min $\mathrm{Koh}^{2,4}$, Min Jin Go', Tae- \\ Ho Kim ${ }^{2,3}$, Jung Min Hong, Eui Kyun Park ${ }^{2,3}$, \\ Shin-Yoon $\mathrm{Kim}^{5 *}$ and Jong-Young Lee ${ }^{1 *}$
}

${ }^{1}$ The Center for Genome Science, National Institute of Health, Seoul 122-701, Korea, ${ }^{2}$ Skeletal Diseases Genome Research Center, Kyungpook National University Hospital, Daegu 700-412, Korea, ${ }^{3}$ Deparement of Pathology and Regenerative Medicine, School of Dentistry, Kyungpook National University, Daegu 700-412, Korea, ${ }^{4}$ Division of Endocrinology and Metabolism, University of Ulsan College of Medicine, Asan Medical Center, Seoul 138-736, Korea, ${ }^{5}$ Deparement of Orthopedic Surgery, School of Medicine, Kyungpook National University, Daegu 700-412, Korea

\begin{abstract}
Osteoporosis is characterized by impaired osteogenesis. $\mathrm{BMD}$ is a major determinant of bone strength. The role of the VDR gene in predisposition to primary osteoporosis has been recognized. However, population-based case-control studies have been reported controversial results for known candidate genes in an ethnically distinct group. To determine the genetic effects of $V D R$ variants on osteoporosis and BMD, we directly sequenced the $V D R$ gene in 24 unrelated Korean individuals and identified eighteen sequence variants. We investigated the potential involvement of eight SNPs in osteoporosis in postmenopausal women $(\mathrm{n}=729)$. Two SNPs (LD) in intron 2, $-5294 G>C$ (rs2238135) and $-4817 G>A$ (rs17882443) showed the evidence of association with enhanced BMD of the femoral neck ( $p_{\text {additive }}=0.031$ for rs2238135; $p_{\text {additive }}=0.017$ and $p_{\text {dominant }}=$ 0.019 for 17882443). Moreover, $V D R-4817 G>A$ was significantly associated with protective effect on all fracture risk ( precessive $=0.035, \mathrm{OR}=0.2,95 \% \mathrm{Cl}=0.05 \sim 0.89$ ), and tended to be higher BMD values at various proximal femur sites. Therefore, we suggest that the $-4817 G>A$
\end{abstract}

*Corresponding author: E-mail syukim@wmail.knu.ac.kr

Tel +82-53-475-9735, Fax +82-2-422-6605

E-mail leejy63@nih.go.kr

Tel +82-2-380-2259, Fax +82-2-354-1063

Accepted 10 March 2009

${ }^{\dagger}$ Equal contributors. may be useful genetic marker for vitamin D-related metabolism and may have an important role in the increased BMD of the proximal femur in postmenopausal Korean women.

Keywords: BMD, fracture, osteoporosis, polymorphism, VDR

\section{Introduction}

Osteoporosis is called "the silent bone disease", characterized by compromised bone strength, predisposes individuals to increased risk of fracture, especially of the hip and vertebra in postmenopausal women (Eisman, 1999; Hwang et al., 2006). Bone loss from an imbalanced remodeling between osteoclastic resorption and osteoblastic formation is observed at the time of menopause, mainly due to estrogen deficiency and calciotropic hormone insufficiency such as vitamin D (Boyle et al., 2003; Harada \& Rodan, 2003; Khosla, 2001).

Vitamin $D$ effects on bone are mediated through the vitamin $\mathrm{D}$ receptor (VDR), a nuclear transcription factor that regulates bone formation, bone resorption, and calcium homeostasis by interacting with vitamin $D$ response elements (VDREs) within Vitamin D target genes. Allelic variation in the VDR gene explains $75 \%$ of the genetic variability in BMD used as a proxy measure (Eisman, 1999; Liu et al., 2003; Morrison et al., 1994).

Since the first association by Morrison et al., allelic variations in genetic regulation of BMD have been subsequently studied in candidate genes related to important elements of bone mineral homeostasis, bone remodeling and bone matrix composition. These approach were practically performed by restriction fragment length polymorphisms (RFLPs) on various populations: Caucasians (Deng et al., 1999; Langdahl et al., 2000; Quesada et al., 2004), African-Americans (Zmuda et al., 1999; Harris et al., 1997), Mexican-Americans (Kammerer et al., 2004; McClure et al., 1997), and Asians (Mitra et al., 2006; Morita et al., 2004; Yamada et al., 2003; Zhang et al., 2004). Ethnicity was shown to be one of the important factors affecting BMD (Liel et al., 1988; Wang et al., 1997). However, controversial results of interethnic differences in allele or genotype distributions for BMD variation have been evidently presented, and a con- 
sensus on the association with BMD on known candidate genes locus has not been reached yet (Gamero et al., 1995; Peacock, 1995).

In this study, we have analyzed the statistical association of Vitamin $\mathrm{D}$ receptor (VDR) gene polymorphisms with intermediate phenotypes (BMD; major risk factor of osteoporotic fracture) and fracture ( $\mathrm{Fx})$ to address confounding differences in ethnic backgrounds involving sample size and stochastic variability. We also performed an analysis of haplotypes in order to identify interaction of haplogenotypes related with osteoporosis.

\section{Methods}

\section{Subjects}

The study population was composed of apparently healthy postmenopausal Korean women $(n=729)$ who visited the Asan Medical Center (AMC) in Seoul, Korea. Menopause was defined as the absence of menstruation for at least 6 months and was confirmed by measurement of serum follicle-stimulating hormone levels. Women who were prematurely menopausal (aged $<40$ years) were excluded. Those who had taken drugs that might affect bone metabolism for $>6$ months, or within the previous 12 months, were also excluded. Additionally, women were excluded if they had any disease that might affect bone metabolism. The mean age was $58.7 \pm 7.5$ years and the mean number of YSM was 9.4 \pm 7.8 (range $1 \sim 35$ ) years.

\section{BMD measurement}

Areal BMD $\left(\mathrm{g} / \mathrm{cm}^{2}\right)$ at the lumbar spine (L2-L4) and femoral neck was measured using dual-energy $\mathrm{X}$-ray absorptiometry (Lunar equipment, Expert XL, Madison, WIS) in 476 women. In the other 253 women, BMD was measured using Hologic equipment (Hologic, QDR 4500-A, Waltham, MA). The precisions of the Lunar and Hologic equipment, presented as coefficient of variations, were $0.82 \%$ and $0.85 \%$ for the lumbar spine and $1.12 \%$ and $1.20 \%$ for the femoral neck, respectively. These values were obtained by scanning 17 volunteers who were not part of the study; each volunteer underwent five scans on the same day, getting on and off the table between examinations. To derive cross-calibration equations between the two systems, BMD values were measured by the two machines in 109 healthy Korean women (mean age $55 \pm 11$, range $31 \sim 75$ years), and cross-calibration equations were calculated as follows (Oldroyd et al., 2003):

L2-L4 BMD $\left(\mathrm{g} / \mathrm{cm}^{2}\right)$ : Lunar $=1.1287 \times$ Hologic -0.0027
Femoral neck BMD $\left(\mathrm{g} / \mathrm{cm}^{2}\right)$ : Lunar $=1.1556 \times$ Hologic 0.0182

We also obtained BMD values at other proximal femoral sites, all taken after January 2001. The Hologic machine did not measure BMD at the femoral shaft. BMD values at the femoral shaft and at other proximal femur sites (trochanter, total femur, Ward' $s$ triangle) were available for 228 and 319 participants, respectively. Associations between these BMD values and VDR genetic variations were determined using statistical adjustments with the machine as a covariate, because the cross-calibration data are not yet available for Korean women at these sites.

\section{Sequencing of the VDR gene}

We sequenced all $V D R$ exons, including exon-intron boundaries, and the promoter region (ca. $1.5 \mathrm{~kb}$ ), to detect SNPs. We sequenced 24 Korean DNA samples using the ABI PRISM 3730 DNA analyzer (Applied Biosystems, Foster City, CA). Sixteen primer sets for amplification and sequencing analyses were designed based on GenBank sequences (Ref. Seq. of VDR mRNA: NM_001017535.1, and contig: NT_029419.11). Sequence variants were verified by automated sequencing chromatograms. SNPs were detected by multiple alignments of sequences using the Phred/Phrap/Consed package and polyphred (Ewing et al., 1998; Gordon et al., 1998; Nickerson et al., 1997).

\section{Golden gate assay for genotyping}

Genotyping was performed at a multiplex level using the Illumina Golden Gate genotyping system (Oilphant et al., 2002), and data quality was assessed using duplicate DNAs $(n=10)$. The genotype quality score for data retention was set at 0.25 . SNPs that could not satisfy the following criteria were excluded: (i) a minimum call rate of $90 \%$; (ii) no duplicate error; (iii) Hardy-Weinberg equilibrium greater than $\mathrm{p}>0.001$.

\section{Statistics}

The $\chi^{2}$ test was used to determine whether individual variants were in equilibrium at each locus in the population (Hardy-Weinberg equilibrium). We examined Lewontin' $s D^{\prime}\left(I^{\prime} \mid\right)$, and the linkage disequilibrium (LD) coefficient $\gamma^{2}$, between all pairs of biallelic loci. Genotypes were given codes of 0,1 , and 2 for the additive model; 0,1 , and 1 for the dominant model; and 0 , 0 , and 1 for the recessive model. Multiple regression analyses of BMD at the lumbar spine and femoral neck 
were performed using age, YSM, weight, and height, as covariates. Associations of BMD values at other proximal femur sites, such as the total femur, the trochanter, Ward's triangle, and the shaft, with VDR genotypes, were determined after further statistical adjustments made necessary by the choice of bone densitometer, because cross-calibration data are not available, to date, for these values in Korean women. The genotype distributions between participants with or without fracture were analyzed using a logistic regression model controlling for age, YSM, weight, and height.

\section{Results}

To investigate the genetic effects of $V D R$ variants on BMD and osteoporosis, we sequenced all the VDR exons and their boundaries including $1.5 \mathrm{~kb}$ of the 5 ' flanking region and identified eighteen polymorphisms three were located in the promoter, three in coding regions of exons (two synonymous and one non-syn.), nine in the 3'-untranslated regions (UTRs), and three in the introns. We genotyped the eight selected SNPs for association studies in postmenopausal women $(n=729)$. Clinical profiles and the correlations between BMD and age, weight, height, and years since menopause (YSM) are listed in Table 1. The mean age of the participants was $58.7 \pm 7.5$ years (range $43 \sim 82$ years), and the mean YSM was $9.5 \pm 7.8$ years (range $1 \sim 32$ years). As expected, age and YSM correlated negatively with BMD at both the lumbar spine and femoral neck. Weight and height correlated positively with BMD at both sites. In these participants, the genotype frequency of each of

Table 1. Clinical profiles and multiple regression analyses of bone mineral density (BMD) $\left(\mathrm{g} / \mathrm{cm}^{2}\right)$ in postmenopausal women $(n=729)$

\begin{tabular}{|c|c|c|c|c|c|c|c|}
\hline \multicolumn{2}{|c|}{ Clinical profiles } & \multicolumn{3}{|c|}{ Lumbar spine BMD } & \multicolumn{3}{|c|}{ Femoral neck BMD } \\
\hline Variables & Mean $( \pm \mathrm{SD})$ & $\beta$ & SE & $\mathrm{p}$-value & $\beta$ & SE & $\mathrm{p}$-value \\
\hline Age (years) & $58.69( \pm 7.5)$ & -0.004 & 0.002 & 0.018 & -0.002 & 0.001 & 0.077 \\
\hline Weight (kg) & $56.24( \pm 7.1)$ & 0.006 & 0.001 & 0.000 & 0.004 & 0.001 & 0.000 \\
\hline Height $(\mathrm{cm})$ & $155.04( \pm 5.3)$ & 0.001 & 0.001 & 0.103 & 0.001 & 0.001 & 0.560 \\
\hline \multirow[t]{2}{*}{ YSM (years) } & $9.44( \pm 7.8)$ & -0.005 & 0.002 & 0.005 & -0.004 & 0.001 & 0.006 \\
\hline & & \multicolumn{3}{|c|}{ Adjusted $R^{2}=0.225$} & \multicolumn{3}{|c|}{ Adjusted $R^{2}=0.198$} \\
\hline
\end{tabular}

*Values are presented as means $( \pm \mathrm{SDs})$ unless otherwise specified. YSM: years since menopause; $\beta$ : regression coefficient; SE: standard error.

Table 2. Frequencies of VDR polymorphisms in postmenopausal women

\begin{tabular}{|c|c|c|c|c|c|c|c|c|c|}
\hline \multirow{2}{*}{$\begin{array}{c}\text { Loci } \\
-5591 T>C\end{array}$} & \multirow{2}{*}{$\begin{array}{c}\text { Position } \\
\text { (Amino acid change) } \\
\text { Intron2 }\end{array}$} & \multirow{2}{*}{$\begin{array}{c}\text { rs ID } \\
\text { rs2853564 }\end{array}$} & \multicolumn{4}{|c|}{ Genotype } & \multirow{2}{*}{$\begin{array}{l}\text { MAF } \\
0.297\end{array}$} & \multirow{2}{*}{$\begin{array}{c}\text { Heterozygosity } \\
0.417\end{array}$} & \multirow{2}{*}{$\begin{array}{c}H W E^{\circ} \\
0.623\end{array}$} \\
\hline & & & $\mathrm{T}$ & CT & C & $\mathrm{N}$ & & & \\
\hline & & & 356 & 308 & 61 & 725 & & & \\
\hline \multirow[t]{2}{*}{$-5402 G>A$} & Intron2 & rs11574034 & $G$ & $\mathrm{GA}$ & A & $N$ & 0.000 & - & - \\
\hline & & & 729 & 0 & 0 & 729 & & & \\
\hline \multirow[t]{2}{*}{$-5294 G>C$} & Intron2 & rs2238135 & $G$ & $C G$ & C & $\mathrm{N}$ & 0.279 & 0.402 & 0.913 \\
\hline & & & 379 & 291 & 57 & 727 & & & \\
\hline \multirow[t]{2}{*}{$-4926 A>G$} & Intron2 & rs11574035 & $A$ & $A G$ & $G$ & $N$ & 0.001 & 0.001 & 0.985 \\
\hline & & & 728 & 1 & 0 & 729 & & & \\
\hline \multirow[t]{2}{*}{$-4817 G>A$} & Intron2 & rs17882443 & $G$ & $A G$ & A & $N$ & 0.222 & 0.346 & 0.668 \\
\hline & & & 439 & 256 & 34 & 729 & & & \\
\hline \multirow[t]{2}{*}{$-4257 G>A$} & Intron2 & rs11574038 & $G$ & $\mathrm{GA}$ & A & $\mathrm{N}$ & 0.000 & - & - \\
\hline & & & 729 & 0 & 0 & 729 & & & \\
\hline \multirow[t]{2}{*}{$-3949 C>T$} & Intron2 & rs11574039 & $\mathrm{C}$ & CT & $\mathrm{T}$ & $N$ & 0.000 & - & - \\
\hline & & & 729 & 0 & 0 & 729 & & & \\
\hline \multirow[t]{2}{*}{$+34169 C>T$} & Exon11 & rs11574115 & C & CT & $\mathrm{T}$ & $\mathrm{N}$ & 0.000 & - & - \\
\hline & (T362I) & & 729 & 0 & 0 & 729 & & & \\
\hline
\end{tabular}

${ }^{a} \mathrm{p}$-values of deviation from Hardy-Weinberg Equilibrium among all subjects. MAF: minor allele frequency. 
A. Map of VDR (vitamin D (1,25- dihydroxyvitamin D3) receptor) on chromosome 12 q13.11 (41.2 kb) NM_001017535.1

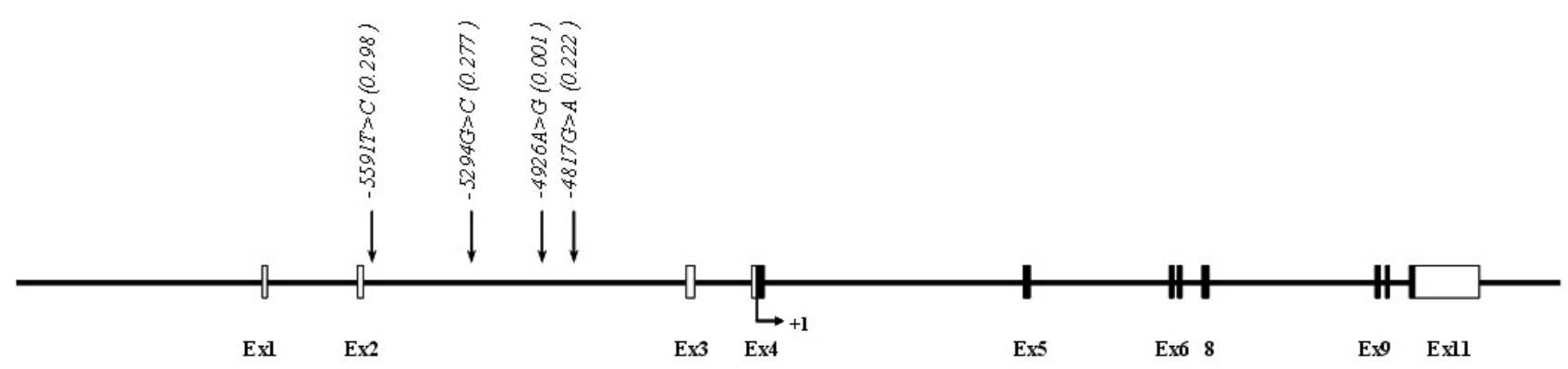

B. Haplotypes in $V D R$

\begin{tabular}{|c|c|c|c|c|c|}
\hline Hap. & 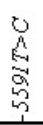 & 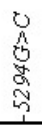 & $\begin{array}{l}\text { b } \\
\text { A } \\
\delta \\
\alpha \\
\alpha \\
\end{array}$ & 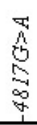 & Freq \\
\hline$h t 1$ & $\mathrm{~T}$ & $\mathrm{G}$ & $\mathrm{A}$ & $\mathrm{G}$ & 0.430 \\
\hline$h t 2$ & $\mathrm{C}$ & $\mathrm{G}$ & A & $\mathrm{G}$ & 0.290 \\
\hline$h t 3$ & $\mathrm{~T}$ & C & A & A & 0.219 \\
\hline$h t 4$ & $\mathrm{~T}$ & C & A & $\mathrm{G}$ & 0.053 \\
\hline$h t 5$ & C & C & A & $\mathrm{G}$ & 0.005 \\
\hline ht 6 & $\mathrm{~T}$ & $\mathrm{G}$ & A & A & 0.002 \\
\hline$h t 7$ & $\mathrm{C}$ & G & $\mathrm{G}$ & G & 0.001 \\
\hline$h t 8$ & $\mathrm{C}$ & $\mathrm{G}$ & A & A & 0.001 \\
\hline
\end{tabular}

C. LDs among VDR polymorphisms

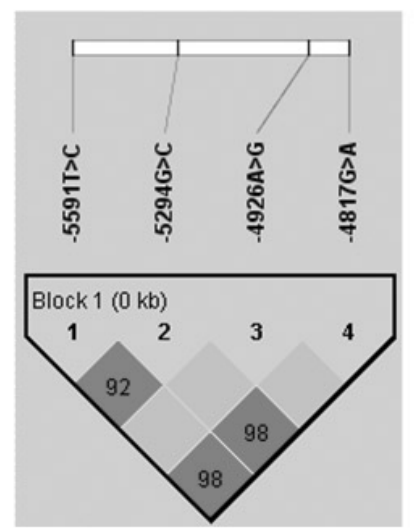

Fig. 1. Gene maps, haplotypes and LD coefficients of VDR. Coding exons are marked by black blocks, and 5'- and 3'UTRs with white blocks. The first base of the translation start site is denoted nucleotide ' +1 '. Polymorphisms genotyped in a larger population $(n=729)$. The frequencies of polymorphisms not subject to larger-scale genotyping were based on sequence data $(\mathrm{n}=24)$. (A) Polymorphisms identified in VDR on chromosome 12q13.11 (Ref. Genome Seq. NM_001017535.1). (B) Haplotypes of VDR. (C) Linkage disequilibrium coefficients LD and LD blocks among VDR polymorphisms.

the eight SNPs studied is shown in Table 2; genotype distributions were in Hardy-Weinberg equilibrium $(\mathrm{p}>$ $0.001)$. The $V D R-5402 G>A,-4926 A>G,-4257 G>A$, $-3949 C>T$ and $+34169 C>T$ SNPs were extremely rare or monomorphic in our subjects. Four common haplotypes (freq. $>0.05$ ) in LD block accounted for $43.0 \%$ (ht-1), 29.0\% (ht-2), 21.9\% (ht-3) and 5.3\% (ht-4) of the distribution, and were used for further analysis (Fig. 1).

We found that $-4817 G>A$ was significantly associated with the risk of all fracture $(\mathrm{p}=0.035)$. The minor allele $(\mathrm{A})$ of $-4817 G>A$ in intron region showed susceptibility to the risk of fracture in the recessive $(\mathrm{p}=$ $0.035, \mathrm{OR}=0.2,95 \% \mathrm{Cl}=0.05 \sim 0.89)$. Consistent with fracture result, VDR-ht3 (TCAA) (Fig. 1B) comprising risk allele also showed the evidence of association with fracture risk by protective effect $(p=0.05, O R=0.23,95 \% \mathrm{Cl}$ $=0.05-1$ ), although the statistical significance was marginal (Table 3 ).
In logistic regression analysis adjusted for confounding variables, we found that the $V D R-4817 G>A$ and $V D R$-ht3 were significantly associated with the BMD of various proximal femur sites as well as femoral neck. $V D R-4817 G>A$ (rs17882443) showed a significant association with BMD at the femoral neck $(\mathrm{p}=0.017$ and $0.019)$, trochanter $(p=0.035$ and 0.014$)$, shaft $(p=0.012$ and 0.020$)$, and total femur $(p=0.030$ and 0.016$)$ in the additive and dominant models, respectively (Table 4). In addition, $-5591 T>C$ in LD block was also associated with higher $\mathrm{BMD}$ of femoral neck $\left(p_{\text {additive }}=0.031\right)$ and shaft $\left(p_{\text {additive }}=0.021\right.$ and $\left.p_{\text {dominan }}=0.018\right)$, respectively (data not shown). VDR-ht3 was associated with increased BMD values of the femoral neck $\left(p_{\text {additive }}=0.028\right.$ and $\left.p_{\text {dominant }}=0.034\right)$, trochanter $\left(p_{\text {additive }}=0.042\right.$ and $p_{\text {do- }}$ minant $=0.017)$, shaft $\left(p_{\text {additive }}=0.014, p_{\text {dominant }}=0.024\right.$ and $p_{\text {re- }}$ cessive $=0.039)$, and total femur $\left(p_{\text {additive }}=0.034\right.$ and $p_{\text {dominant }}$ $=0.019$ ), respectively (Table 4$)$. 
Table 3. Logistic analysis of VDR polymorphisms in relation to fracture risk in postmenopausal women

\begin{tabular}{|c|c|c|c|c|c|c|c|c|}
\hline \multirow{2}{*}{ Loci } & \multirow{2}{*}{$\begin{array}{l}\text { Case } \\
\text { (165) }\end{array}$} & \multirow{2}{*}{$\begin{array}{c}\text { Control } \\
(563)\end{array}$} & \multicolumn{2}{|l|}{ Additive } & \multicolumn{2}{|c|}{ Dominant } & \multicolumn{2}{|c|}{ Recessive } \\
\hline & & & OR $(95 \% \mathrm{Cl})$ & $p$ & OR (95\% Cl) & $p$ & OR (95\% Cl) & $p$ \\
\hline$-5591 T>C$ & 0.299 & 0.296 & $0.98(0.74 \sim 1.31)$ & 0.909 & $1(0.69 \sim 1.46)$ & 0.995 & $0.92(0.48 \sim 1.78)$ & 0.804 \\
\hline$-5294 G>C$ & 0.264 & 0.283 & $0.94(0.69 \sim 1.26)$ & 0.662 & $1.1(0.76 \sim 1.61)$ & 0.612 & $0.42(0.18 \sim 1)$ & 0.050 \\
\hline$-4926 A>G$ & 0.000 & 0.001 & - & 0.984 & - & 0.984 & - & - \\
\hline$-4817 G>A$ & 0.212 & 0.225 & $0.91(0.65 \sim 1.26)$ & 0.552 & $1.05(0.72 \sim 1.54)$ & 0.800 & $0.2(0.05 \sim 0.89)$ & 0.035 \\
\hline$V D R \_h t 1$ & 0.439 & 0.426 & $1.08(0.83 \sim 1.41)$ & 0.577 & $1.3(0.86 \sim 1.96)$ & 0.209 & $1.13(0.64 \sim 2.02)$ & 0.673 \\
\hline VDR_ht2 & 0.297 & 0.287 & $1(0.74 \sim 1.33)$ & 0.978 & $1(0.69 \sim 1.46)$ & 0.985 & $0.91(0.45 \sim 1.84)$ & 0.787 \\
\hline VDR_ht3 & 0.212 & 0.221 & $0.93(0.67 \sim 1.29)$ & 0.657 & $1.09(0.74 \sim 1.6)$ & 0.665 & $0.23(0.05 \sim 1)$ & 0.050 \\
\hline$V D R \_h t 4$ & 0.052 & 0.054 & $1.01(0.57 \sim 1.79)$ & 0.979 & $1.05(0.55 \sim 1.99)$ & 0.893 & $0.68(0.07 \sim 6.93)$ & 0.741 \\
\hline
\end{tabular}

Genotype distributions and p-values for logistic analyses of three alternative models (additive, dominant and recessive models) controlling for age, weight, height, year since menopause, and type of evaluation machine, as covariates, are shown.

Table 4. Regression analysis of bone mineral density (BMD) $\left(\mathrm{g} / \mathrm{cm}^{2}\right)$ of various sites in relation to VDR polymorphisms in postmenopausal women

\begin{tabular}{lccccccc}
\hline \multicolumn{1}{c}{ Bone loci } & Loci & $\mathrm{C} / \mathrm{C}^{*}$ & $\mathrm{C} / \mathrm{R}$ & $\mathrm{R} / \mathrm{R}$ & $P a^{\dagger}$ & $P b$ & $P C$ \\
\hline Femoral neck & $-4817 G>A$ & $439(0.7 \pm 0.14)$ & $256(0.68 \pm 0.12)$ & $34(0.67 \pm 0.11)$ & 0.017 & 0.019 & 0.242 \\
& $V D R \_h t 3$ & $443(0.7 \pm 0.14)$ & $252(0.68 \pm 0.12)$ & $34(0.67 \pm 0.11)$ & 0.028 & 0.034 & 0.154 \\
\multirow{2}{*}{ Trochanter } & $-4817 G>A$ & $189(0.59 \pm 0.13)$ & $119(0.56 \pm 0.1)$ & $12(0.61 \pm 0.14)$ & 0.035 & 0.014 & 0.970 \\
& $V D R \_h t 3$ & $191(0.59 \pm 0.13)$ & $117(0.56 \pm 0.1)$ & $12(0.61 \pm 0.14)$ & 0.042 & 0.017 & 0.624 \\
Shaft & & & & & & & \\
& $-4817 G>A$ & $129(1.01 \pm 0.19)$ & $90(0.96 \pm 0.16)$ & $10(0.98 \pm 0.21)$ & 0.012 & 0.020 & 0.133 \\
& $V D R \_h t 3$ & $130(1.01 \pm 0.19)$ & $89(0.96 \pm 0.16)$ & $10(0.98 \pm 0.21)$ & 0.014 & 0.024 & 0.039 \\
Total femur & $-4817 G>A$ & $189(0.8 \pm 0.14)$ & $119(0.76 \pm 0.13)$ & $12(0.81 \pm 0.16)$ & 0.030 & 0.016 & 0.783 \\
& $V D R \_h t 3$ & $191(0.8 \pm 0.14)$ & $117(0.77 \pm 0.13)$ & $12(0.81 \pm 0.16)$ & 0.034 & 0.019 & 0.477 \\
\hline
\end{tabular}

BMD values and $p$-values for regression analyses of three alternative models (additive, dominant, and recessive) controlling for age, weight, height, and years since menopause, as covariates, are shown.

${ }^{*} \mathrm{C} / \mathrm{C}, \mathrm{C} / \mathrm{R}$, and $\mathrm{R} / \mathrm{R}$ represent homozygotes for the common allele, and heterozygotes and homozygotes for the rare allele, respectively.

${ }^{\dagger} \mathrm{Pa}, \mathrm{Pb}$ and $P c$ are $\mathrm{p}$ values of additive, dominant, and recessive models for multiple regression analysis, respectively.

${ }^{\dagger}$ Means \pm standard deviations of BMD $\left(\mathrm{g} / \mathrm{cm}^{2}\right)$.

\section{Discussion}

In the present study, we closely examined VDR gene region polymorphisms for the association of the genetic variations with fracture risk and quantitative traits (BMD values). In this regard, the VDR polymorphisms are expected to provide more extensive genetic information for osteoporosis or its related fracture, compared with previous standardized testing such as RFLP based on only four common endonuclease, Apal (rs17879735), Bsm I (1544410), FokI (17881966), and TaqI (rs1788009). VDR, an intracellular receptor that specifically binds the active form of vitamin $D$ (1,25-dihydroxyvitamin D3 or calcitriol) and interacts with target-cell nuclei to produce a variety of biologic effects, contains 11 exons and spans over $41.2 \mathrm{~kb}$ on chromosome 12q13.11 (Baker et al., 1988).

When haplotype LD was analyzed based on the individual genotype information of selected SNPs, VDR$h$ t3 was significantly associated with all fracture risk (Table 3). Among SNPs of VDR-ht3, the minor allele of $-4817 G>A$ was also associated with protective effect of fracture. Interestingly, the effects of VDR $-4817 G>A$ on quantitative BMD of the femoral neck was allele-dose dependent; the highest BMD being found in homozygotes for the common allele $(0.7 \pm 0.14)$, intermediate BMD in heterozygotes $(0.68 \pm 0.12)$, and the lowest BMD in homozygotes for the rare allele $(0.67 \pm$ 
0.11 ) (Table 4). In addition, both the $-4817 G>A$ and $V D R$-ht3 comprising risk allele also showed the evidence of association with higher BMD values of various proximal femur sites.

In our results, the VDR polymorphisms are associated with higher BMD of proximal femur sites as well as femoral neck, but not with that of the lumbar spine. Since the femoral shaft, trochanter and total femur have higher cortical bone content that the lumbar spine, these polymorphisms may influence cortical bone strength. Accordingly, BMD values at femur neck predict fractures better than those at vertebral BMD. Because the mean age of our subjects was 58.7 years, these results may have been due to osteoarthritis, degenerative changes such as bony spurs, or aortic calcification which occur more often in the elderly individuals, and therefore may have falsely changed BMD measured by dual energy X-ray absorptiometry (Burger et al., 1996). Although multiple environmental factors are involved in the pathogenesis of osteoporosis, genetic factors are also largely responsible for bone mass, accounting for about $50-85 \%$ of the variance in BMD on the basis of twin and family studies (Arden and Spector, 1997; Gueguen et al., 1995; $\mathrm{Ng}$ et al., 2006). However, the heritability of fractures has been estimated to lie only between 25 and 35\% (Deng et al., 2000; MacGregor et al., 2000), which is much lower than the heritability of BMD values, many fall-related factors other than BMD must contribute to fracture risk.

The genetic effects of VDR polymorphisms on BMD are not dramatic. Because the associated $p$-values did not retain statistical significance for multiple comparisons. If Bonferroni correction were strictly adopted, associated $p$-values could not retain all significances. However, although there is a chance of type I error due to multiple comparisons, when considering the facts that consistent positive signals at the same sites $(-4817 G>A$ and $V D R$-ht 3) with various bone-related phenotypes, the significance of associations might be reasonable. Nevertheless, it might be worthwhile to follow up on the effects of this important common gene with larger cohort studies, considering its vital role in bone mineral metabolism. Further biological and functional evidence would be needed to confirm the suggestive association of $V D R$ variants with bone-related phenotypes.

After a multitude of studies, several standardized variations by RFLP have been investigated for associations with fracture and BMD, but study results are in consistent (Dvomyk et al., 2004; Horst-Sikorska et al., 2007; Kiel et al., 2007; Long et al., 2004; Uitterlinden et al., 2006). have performed a large-scale meta-analysis of studies from prospective multicenter to investigate the effect on fracture incidence of four restriction-fragment-length polymorphisms (Fokl, Bsml, Apal, and
Taq I). These polymorphisms were not associated with lumbar spine or femoral neck BMD. However, these results are inconsistent with our investigations carried out for Korean menopausal women. This is probably due to the fact that the study design did not examine all $V D R$ polymorphisms, contribute more to identify genetic risk factors. Our results suggest that VDR polymorphisms and haplotypes provide more genetic information on osteoporosis risk.

In conclusion, we identified 18 polymorphisms of VDR in Korean population, found that $-4817 G>A$ ( $\mathrm{rs} 17882443$ ) and VDR-ht3 were significantly associated with enhanced BMD and fracture risk protection as genetic factor. Our observations suggest that these sequencebased variants are candidates for genetic determinants of BMD of the hip in postmenopausal women.

\section{Acknowledgments}

This work was supported by intramural grants from the Korea National Institute of Health, the Korea Center for Disease Control of the Republic of Korea (Project No: 347-6111-211), and a grant from the Korea Health 21 R\&D Project, Ministry of Health \& Welfare, Republic of Korea (Project No.: 01-PJ3-PG6-01GN11-0002).

\section{References}

Arden, N.K., and Spector, T.D. (1997). Genetic influences on muscle strength, lean body mass, and bone mineral density: a twin study. J. Bone Miner. Res. 12, 2076-2081.

Baker, A.R., McDonnell, D.P., Hughes, M., et al. (1988). Cloning and expression of full-length cDNA encoding human vitamin D receptor. Proc Natl Acad Sci U.S.A. 85, 3294-3298

Boyle, W.J., Simonet, W.S., and Lacey, D.L. (2003). Osteoclast differentiation and activation. Nature 423, 337-342.

Burger, H., van Daele, P.L., Odding, E., et al. (1996). Association of radiographically evident osteoarthritis with higher bone mineral density and increased bone loss with age. The Rotterdam Study. Arthritis Rheum. 39, 81-86.

Deng, H.W., Chen, W.M., Recker, S., et al. (2000). Genetic determination of Colles' fracture and differential bone mass in women with and without Colles' fracture. $J$. Bone Miner Res. 15, 1243-1252.

Deng, H.W., Li, J., Li, J.L., et al. (1999). Association of VDR and estrogen receptor genotypes with bone mass in postmenopausal Caucasian women: different conclusions with different analyses and the implications. Osteoporos Int. 9,499-507.

Dvornyk, V., Long, J.R., Xiong, D.H., et al. (2004). Current limitations of SNP data from the public domain for studies of complex disorders: a test for ten candidate genes for obesity and osteoporosis. BMC Genet. 5, 4.

Eisman, J.A. (1999). Genetics of osteoporosis. Endocr Rev. 20, 788-804. 
Ewing, B., Hillier, L., Wendl, M.C., et al.(1998). Base-calling of automated sequencer traces using phred. I. Accuracy assessment. Genome Res. 8, 175-185.

Garnero, P., Borel, O., Sornay-Rendu, E., et al. (1995). Vitamin D receptor gene polymorphisms do not predict bone turnover and bone mass in healthy premenopausal women. J. Bone Miner. Res. 10, 1283-1288.

Gordon, D., Abajian, C., and Green, P. (1998). Consed: a graphical tool for sequence finishing. Genome Res. 8, 195-202.

Gueguen, R., Jouanny, P., Guillemin, F., et al. (1995). Segregation analysis and variance components analysis of bone mineral density in healthy families. J. Bone Miner. Res. 10, 2017-2022.

Harada, S., and Rodan, G.A. (2003). Control of osteoblast function and regulation of bone mass. Nature 423, 349-355.

Harris, S.S., Eccleshall, T.R., Gross, C., et al. (1997). The vitamin $\mathrm{D}$ receptor start codon polymorphism (Fokl) and bone mineral density in premenopausal American black and white women. J. Bone Miner. Res. 12, 1043-1048.

Horst-Sikorska, W., Kalak, R., Wawrzyniak, A., et al. (2007). Association analysis of the polymorphisms of the VDR gene with bone mineral density and the occurrence of fractures. J. Bone Miner Metab. 25, 310-319.

Hwang, J.Y., Lee, J.Y., Park, M.H., et al. (2006). Association of PLXNA2 polymorphisms with vertebral fracture risk and bone mineral density in postmenopausal Korean population. Osteoporos Int. 17, 1592-1601.

Kammerer, C.M., Dualan, A.A., Samollow, P.B., et al. (2004). Bone mineral density, carotid artery intimal medial thickness, and the vitamin D receptor Bsml polymorphism in Mexican American women. Calcif Tissue Int. 75, 292-298.

Khosla, S. (2001). Minireview: the OPG/RANKL/RANK system. Endocrinology 142,5050-5055.

Kiel, D.P., Demissie, S., Dupuis, J., et al. (2007). Genomewide association with bone mass and geometry in the Framingham Heart Study. BMC Med Genet. Suppl:8-1, S14.

Langdahl, B.L., Gravholt, C.H., Brixen, K., et al. (2000). Polymorphisms in the vitamin $\mathrm{D}$ receptor gene and bone mass, bone turnover and osteoporotic fractures. Eur. J. Clin. Invest. 30, 608-617.

Liel, Y., Edwards, J., Shary, J., et al. (1988). The effects of race and body habitus on bone mineral density of the radius, hip, and spine in premenopausal women. J. Clin Endocrinol Metab. 66, 1247-1250.

Liu, Y.Z., Liu, Y.J., Recker, R.R., et al.(2003). Molecular studies of identification of genes for osteoporosis: the 2002 update. J. Endocrinol. 177, 147-196.

Long, J.R., Zhao, L.J., Liu, P.Y., et al. (2004). Patterns of linkage disequilibrium and haplotype distribution in disease candidate genes. BMC Genet. 5, 11.

MacGregor, A., Snieder, $H_{\text {., }}$ and Spector, T.D. (2000). Genetic factors and osteoporotic fractures in elderly people. Twin data support genetic contribution to risk of fracture. BMJ 320, 1669-1670.

McClure, L., Eccleshall, T.R., Gross, C., et al. (1997). Vitamin $D$ receptor polymorphisms, bone mineral density, and bone metabolism in postmenopausal Mexican-American women. J. Bone Miner. Res. 12, 234-240.
Mitra, S., Desai, M., and Ikram Khatkhatay, M., (2006). Vitamin $D$ receptor gene polymorphisms and bone mineral density in postmenopausal Indian women. Maturitas $55,27-35$.

Morita, A., Iki, M., Dohi, Y., et al. (2004). Prediction of bone mineral density from vitamin $D$ receptor polymorphisms is uncertain in representative samples of Japanese Women. The Japanese Population-based Osteoporosis (JPOS) Study. Int. J. Epidemiol. 33, 979-988.

Morrison. N.A., Qi, J.C., Tokita, A., et al. (1994). Prediction of bone density from vitamin $D$ receptor alleles. Nature 367, 284-287.

Ng, M.Y., Sham, P.C., Paterson, A.D., et al. (2006). Effect of environmental factors and gender on the heritability of bone mineral density and bone size. Ann. Hum. Genet. 70, 428-438.

Nickerson, D.A., Tobe, V.O., and Taylor, S.L. (1997). PolyPhred: automating the detection and genotyping of single nucleotide substitutions using fluorescence-based resequencing. Nucleic Acids Res. 25, 2745-2751.

Oldroyd, B., Smith, A.H., and Truscott, J.G. (2003). Cross-calibration of GE/Lunar pencil and fan-beam dual energy densitometers--bone mineral density and body composition studies. Eur. J. Clin. Nutr. 57, 977-987.

Oliphant, A., Barker, D.L., Stuelpnagel, J.R., et al. (2002). BeadArray technology: enabling an accurate, cost-effective approach to high-throughput genotyping. Biotechniques Suppl:56-8, 60-61.

Peacock, M. (1995). Vitamin D receptor gene alleles and osteoporosis: a contrasting view. J. Bone Miner. Res. 10, 1294-1297.

Quesada, J.M., Casado, A., Diaz, C., et al. (2004). Allele-frequency determination of Bsml and Fokl polymorphisms of the VDR gene by quantitative real-time PCR (QRT-PCR) in pooled genomic DNA samples. J. Steroid Biochem Mol Biol. 89-90, 209-214.

Uitterlinden, A.G., Ralston, S.H., Brandi, M.L., et al. (2006). The association between common vitamin $D$ receptor gene variations and osteoporosis: a participant-level metaanalysis. Ann Intern Med. 145, 255-264.

Wang, M.C., Aguirre, M., Bhudhikanok, G.S., et al. (1997). Bone mass and hip axis length in healthy Asian, black, Hispanic, and white American youths. J. Bone Miner Res. 12, 1922-1935.

Yamada, Y., Ando, F., Niino, N., et al. (2003). Association of polymorphisms of interleukin-6, osteocalcin, and vitamin $D$ receptor genes, alone or in combination, with bone mineral density in community-dwelling Japanese women and men. J. Clin. Endocrinol Metab. 88, 3372-3378.

Zhang, Z.L., Qin, Y.J., Huang, Q.R., et al. (2004). Association of estrogen receptor-alpha and vitamin $D$ receptor genotypes with therapeutic response to calcium in postmenopausal Chinese women. Acta Pharmacol Sin. 25, 1690-1697.

Zmuda, J.M., Cauley, J.A., Danielson, M.E., et al. (1999). Vitamin $D$ receptor translation initiation codon polymorphism and markers of osteoporotic risk in older African-American women. Osteoporos Int. 9, 214-219. 